Tiago J. C. Sousa, Vítor Monteiro, J. G. Pinto, Andrés A. Nogueiras Meléndez, João L. Afonso, João L. Afonso

\title{
"Single-Phase Shunt Active Power Filter with UPS Operation using a Bidirectional Dc-Dc Converter for Energy Storage Interface"
}

IEEE IECON Industrial Electronics Conference, pp. 4972-4977, Beijing China, Oct. 2017.

\section{http://ieeexplore.ieee.org/document/8216858/}

DOI: $10.1109 /$ IECON.2017.8216858

ISBN: 978-1-5386-1127-2

This material is posted here with permission of the IEEE. Such permission of the IEEE does not in any way imply IEEE endorsement of any of Group of Energy and Power Electronics, University of Minho, products or services. Internal or personal use of this material is permitted. However, permission to reprint/republish this material for advertising or promotional purposes or for creating new collective works for resale or redistribution must be obtained from the IEEE by writing to pubs-permissions@ieee.org. By choosing to view this document, you agree to all provisions of the copyright laws protecting it.

(C) 2014 IEEE 


\title{
Single-Phase Shunt Active Power Filter with UPS Operation using a Bidirectional Dc-Dc Converter for Energy Storage Interface
}

\author{
Tiago J. C. Sousa ${ }^{1}$, Vítor Monteiro ${ }^{1}$, J. G. Pinto ${ }^{1}$, Andrés A. Nogueiras Meléndez ${ }^{2}$, João L. Afonso ${ }^{1}$ \\ ${ }^{1}$ ALGORITMI Research Centre - University of Minho, Guimarães - Portugal \\ ${ }^{2}$ Departamento de Tecnología Electrónica - University of Vigo, Vigo - Spain \\ ${ }^{1}$ \{tiago.sousa | vitor.monteiro | gabriel.pinto | joao.1.afonso\}@algoritmi.uminho.pt ${ }^{2}$ aaugusto@uvigo.es
}

\begin{abstract}
This paper presents a single-phase shunt active power filter (SAPF) with bidirectional dc-dc converter for uninterruptible power supply (UPS) operation. The proposed system comprises two power converters, namely a dc-ac converter to interface the power grid and a bidirectional isolated dc-dc converter connected to a battery pack, with both converters sharing the same dc-link. The arrangement of the converters allows the operation of the system in three different modes: (1) As SAPF, during normal operation; (2) As off-line UPS, in case of power grid outages; (3) As battery charging system, combined with the operation as SAPF. Simulation results of these three modes are presented in the paper to prove the operation feasibility of the proposed system. A reduced-scale prototype was developed, and the main parameters of the control stage, as well as the implemented control algorithms and power structure, are described in the paper. The experimental results obtained highlight the main benefits of the developed prototype.
\end{abstract}

Keywords-Bidirectional Isolated Dc-Dc Converter, Power Quality, Shunt Active Power Filter, Uninterruptible Power Supply.

\section{INTRODUCTION}

Power electronics has contributed to a better utilization of electric energy. Nonetheless, this development and subsequent proliferation of nonlinear loads connected to the power grid led to substantial harmonic currents circulation, carrying large financial costs that must be mitigated [1][2]. Several solutions have been proposed along the last decades, with the shunt active power filter (SAPF) allowing dynamic compensation of both power factor and harmonic currents demanded by the loads connected to the power grid [3][4]. In practical terms, initially a SAPF was developed based on line frequency commutation, aiming only fundamental reactive power compensation [5], but later a SAPF with switching devices made practicable the harmonic currents compensation [6].

A SAPF is a power electronics device composed by a dc-ac converter, whose connection in parallel with the power grid allows the production of reactive power and harmonic currents. Due to its operation, a SAPF turns the grid currents sinusoidal and in phase with the grid voltages, supplying the loads with active power only. Regarding its importance, research has been widely performed concerning topologies and control strategies for SAPFs [7].

However, power quality problems related with currents are not the only concern in power systems. Voltage related issues represent a vital role in medical facilities and industries [8][9], for instance. Thus, proper foresight is essential to a power system comprising loads that demand a continuous deliver of power. Consequently, it must be equipped with an energy backup and the respective power electronics converters, which can be achieved with an uninterruptible power supply (UPS). In general, a UPS comprises a dc-ac converter to produce the ac voltage to feed the priority loads and an ac-dc or dc-dc converter to charge the batteries. UPS topologies may offer distinct levels of protection, efficiency and cost [10].

Both a SAPF and an off-line UPS are comprised by a dc-ac converter, with the addition of another converter to perform battery charging in the off-line UPS [11]. Hence, by adding a dc-dc converter to interface a battery pack and the SAPF dc-link, a SAPF with off-line UPS capability can be achieved. A modular UPS system combined with a SAPF is proposed in [12] using separate converters. In [13] is investigated the operation of a three-phase SAPF with energy backup, which comprises a non-isolated dc-dc converter, requiring a large battery pack. An off-line UPS with the features of a SAPF was proposed in [14], using a high-frequency transformer in the dc-dc converter. However, it uses a cycloconverter with four bidirectional cells, which causes high conduction losses.

This paper proposes a single-phase SAPF with UPS operation, comprising a grid connected dc-ac converter and a bidirectional isolated dc-dc converter. The dc-ac converter can operate as a harmonic current source (SAPF operation mode), providing the harmonic currents and reactive power demanded by the loads, or as a sinusoidal voltage source, providing uninterruptible power to the loads (UPS operation mode). The bidirectional isolated dc-dc converter is responsible to control the battery charging (which is performed simultaneously to the SAPF operation mode) and to regulate the dc-link voltage of the dc-ac converter during the UPS operation mode. This operation mode is only activated during power outages, where the control system constantly monitors the power grid voltage and changes the operation from SAPF to UPS as soon as a power outage is identified. Besides, the fact of employing an isolated dc-dc converter allows the utilization of a relatively low voltage battery pack, once the high-frequency transformer present in the referred converter allows a higher voltage conversion ratio than non-isolated topologies, which aims to be a significant contribution of the proposed system. 


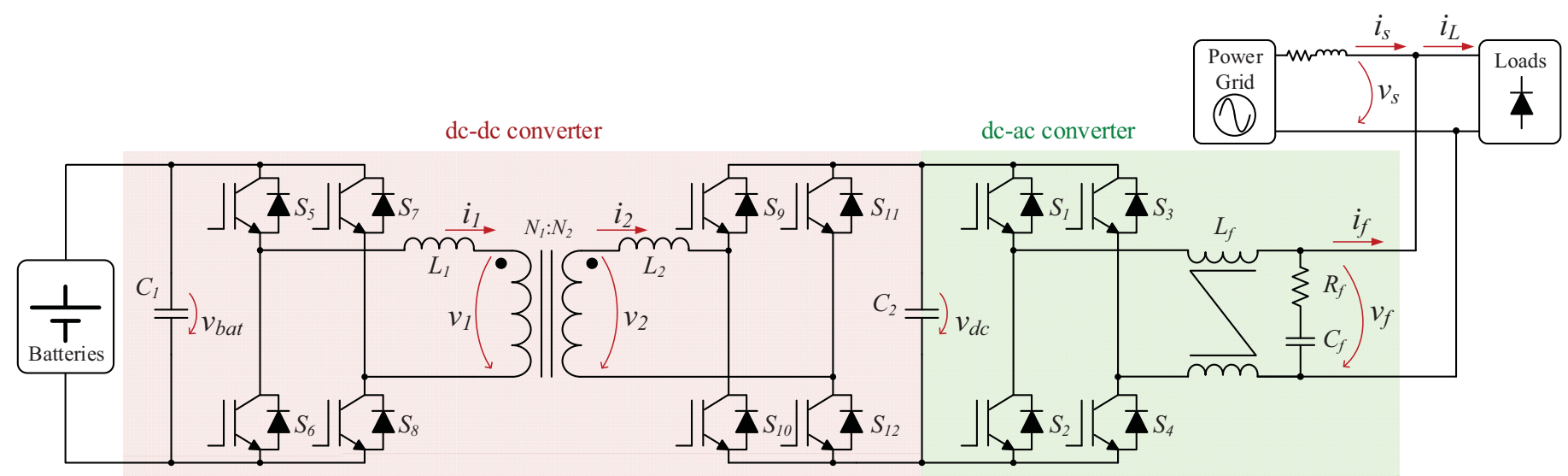

Fig. 1. Schematic of the proposed shunt active power filter (SAPF) with bidirectional dc-dc converter for UPS operation.

\section{PRINCIPLE OF OPERATION}

The present section shows the principle of operation of the proposed SAPF with bidirectional dc-dc converter for UPS operation. A schematic of the proposed system is represented in Fig. 1, where two power converters can be seen: a dc-ac converter and a bidirectional isolated dc-dc converter. Both converters are described in detail during this section.

\section{A. Dc-Ac Converter}

To interface the power grid it is used a voltage-source full-bridge dc-ac converter, which is active in all operation modes. When the system is operating as SAPF, this converter is controlled as a current-source in order to control the grid current. The reference for this current is attained with Fryze-Buchholz-Depenbrock (FBD) power theory [15], where the active power demanded by the loads is calculated with the purpose of determining the components of current desirable to be supplied by the power grid (a sinusoidal current in phase with the power grid voltage). Hence, the SAPF is responsible to provide the harmonic content and the reactive power required by the loads [16]. To achieve a sinusoidal grid reference current in the presence of a distorted grid voltage, in the control theory it must be used the fundamental component of the grid voltage instead of its instantaneous value, which can be achieved through a phase-locked-loop (PLL) algorithm. The applied PLL algorithm is presented in [17]. Besides, the power component present in the calculation contains also the necessary power to regulate the dc-link voltage. This power component is obtained by means of a proportional-integral (PI) controller and denotes an additional power that needs to be absorbed from the power grid. Since the charging of the batteries is accomplished during the operation as SAPF, another power component must be added to the FBD power theory expression, representing the power involved in the dc-dc converter to charge the batteries. Therefore, the SAPF reference current $\left(i_{f}^{*}\right)$ is calculated according to:

$$
i_{f}^{*}=i_{L}-\frac{\left(P+p_{\text {reg }}+p_{\text {bat }}\right)}{V_{S}^{2}} v_{\text {spll }},
$$

where $i_{L}$ is the load current, $P$ is the load demanded active power, $p_{\text {reg }}$ is the dc-link regulation power component, $p_{\text {bat }}$ is the battery charging power, $V_{s}^{2}$ is the squared rms power grid voltage and $v_{\text {spll }}$ is the fundamental component of the power grid voltage achieved by the PLL algorithm. The current produced by the SAPF is controlled by means of a PI with sinusoidal pulse-width modulation (SPWM) technique.

On the other hand, the dc-ac converter is controlled as a sinusoidal voltage source during the UPS operation mode, feeding the priority loads in the occurrence of power outages. The PLL algorithm provides the output reference voltage for the dc-ac converter. The synthesized voltage is controlled using a dual-loop proportional-integral-derivative (PID) controller in order to produce a low distortion voltage in the presence of nonlinear loads. Thus, the first control loop is a PI controller, in which the output voltage is used, whereas the second control loop uses the proportional and derivative components of the output current in order to compensate for high di/dt characteristic of nonlinear loads.

\section{B. Bidirectional Isolated Dc-Dc Converter}

For the dc-dc converter, a voltage-fed dual active bridge topology was chosen. Being an isolated dc-dc converter, both primary and secondary sides are isolated by means of a high-frequency transformer, which also allows large ratio voltage step-up of the batteries (primary side) to the dc-link of the dc-ac converter (shared with the secondary side).

The dual active bridge dc-dc converter, as a bidirectional isolated dc-dc converter, can be controlled by pulse width modulation (PWM), phase shift and its variants. The phase shift modulation technique is largely applied in this type of converters, where both bridges produce a square-wave with a phase difference between them, with the leading bridge providing power to the lagging bridge. The transferred power increases with the phase shift [18]. Moreover, this modulation scheme performs active rectification, which is advantageous in the presence of low voltage values. In contrast, PWM switches one bridge at each time, while the remaining bridge behaves as a diode bridge. This leads to a reduced efficiency especially with low voltage values [19]. In spite of its flexible control, phase shift modulation has disadvantages, such as the 
operation with reactive power. High values of reactive power and consequently large currents tend to be involved when the voltages applied to the transformer windings deviate considerably from the transformer turns ratio, even when the desired power transfer is low. Regarding this problem, phase shift modulation variants were developed, as dual phase shift [20] and triple phase shift [21], which apply two or three different phase shifts to the converter, respectively. Therefore, instead of applying only a phase difference between both bridges, the aforementioned techniques use an additional phase shift between both legs of the same bridge. Due to the additional zero level in the voltage applied to the transformer windings, these modulation schemes contribute to reduce the reactive power and the circulating currents involved. This mitigation can also be achieved by combining both PWM and phase shift modulation techniques [22]. In this context, a duty-cycle controlled phase shift modulation technique was used for power transfer with the purpose of reducing the reactive power and therefore the current stress in the power switches and in the transformer. For the generation of the duty-cycle it is used a PI controller, where high values are obtained when the dc side converter voltages have a quotient similar to the transformer turns ratio and low duty-cycle values when the referred proportion shows a considerable deviation. The phase shift angle is also calculated through a PI controller. As aforementioned, the angle controls the power transfer, performing the battery charging during the SAPF operation mode and regulating the dc-link voltage along the UPS operation mode.

\section{SIMULATION VALIDATION}

This section presents the validation of the proposed system through computer simulations using software PSIM 9.1. In order to evaluate the system performance, this section is divided in three operation modes: SAPF, UPS and battery charging system.

\section{A. Operation as SAPF}

This item shows the operation of the proposed system as SAPF. Concerning the connection to the power grid, the first process of the SAPF control system is the synchronization with the power grid voltage fundamental component, being used the aforementioned PLL algorithm. The next step consists in generating the reference current through FBD power theory, whose actual value is tracked with a PI current controller, as mentioned before in this paper (section II (a)).

Fig. 2 shows the operation of the SAPF towards two different loads, being visible the power grid voltage $\left(v_{s}\right)$ and current $\left(i_{s}\right)$, the load current $\left(i_{L}\right)$ and the compensation current produced by the SAPF $\left(i_{f}\right)$. One of the loads is a full-bridge diode rectifier with output RC parallel load and input inductor, initially connected to the power grid, while the other is a full-bridge diode rectifier with output RL series load, which is connected at $0.1 \mathrm{~s}$. Even during the connection of the load, it is noticeable that the grid current preserves a sinusoidal
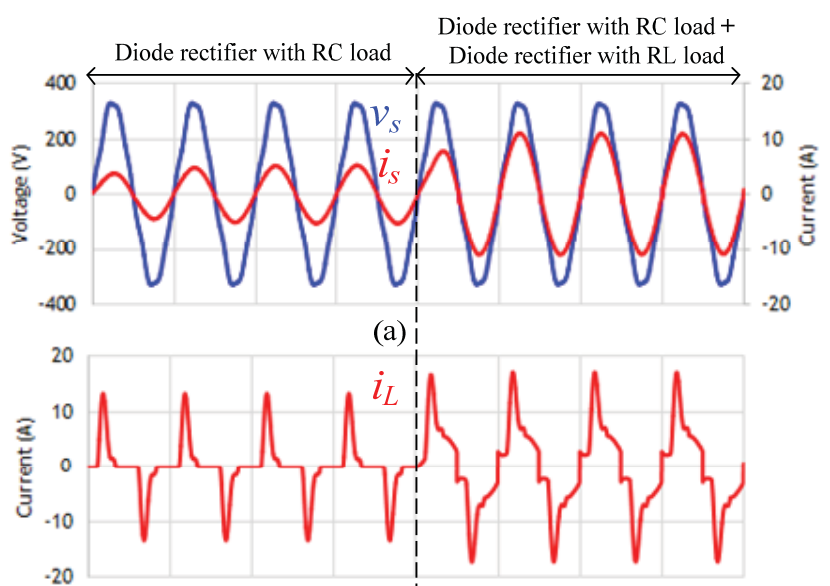

(b) i

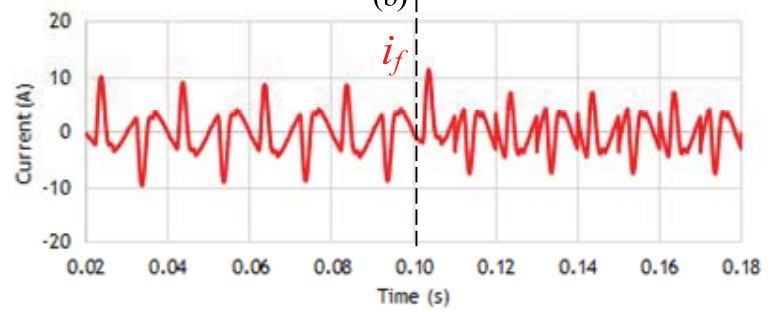

(c)

Fig. 2. Simulation results during normal SAPF operation: (a) Power grid voltage $\left(v_{s}\right)$ and current $\left(i_{s}\right)$; (b) Load current $\left(i_{L}\right)$; (c) SAPF current $\left(i_{f}\right)$.

waveform, evidencing the good transient response of the SAPF control system. In steady state, the grid current is in phase with the grid voltage and has a total harmonic distortion (THD) of $1.1 \%$.

\section{B. Operation as UPS}

This item presents the operation of the proposed system as UPS. As previously referred, this mode of operation is only activated in the presence of power outages, whereby the first algorithm consists in the detection of these events. The half-cycle rms value of the power grid voltage is the chosen method, triggering the UPS operation mode towards a detection of an rms grid voltage below a threshold of $10 \%$ of its nominal value.

Fig. 4 shows the system's transition from SAPF to UPS operation mode, where it can be seen the SAPF output voltage $\left(v_{f}\right)$ and the load current $\left(i_{L}\right)$ drawn by a full-bridge diode rectifier with output capacitor and input inductor. A power outage was generated at $0.105 \mathrm{~s}$, corresponding to a phase angle of $90^{\circ}$ of the power grid voltage. The control system took $1 \mathrm{~ms}$ to acknowledge the power outage. After the detection, the SAPF begins to synthesize a sinusoidal voltage to keep the load fed. As a matter of fact, even with a nonlinear load, the voltage produced by the SAPF in UPS operation mode has a lower THD (1.4\%) when compared to the power grid voltage $(4.8 \%)$, visible between $0.08 \mathrm{~s}$ and $0.105 \mathrm{~s}$. In order to assess the transient response of the UPS operation mode, a series RL load was connected at $0.145 \mathrm{~s}$. As it can be noted, the connection of the load does not lead to significant 


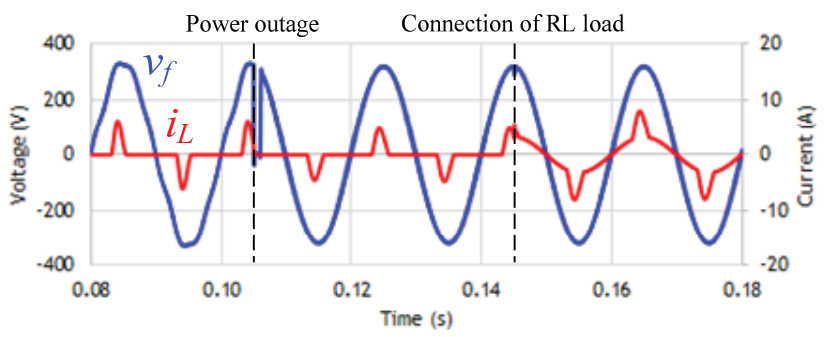

Fig. 4. Simulation results during UPS operation: SAPF output voltage $\left(v_{f}\right)$; Load current $\left(i_{L}\right)$.

disturbances in the produced voltage and its THD remains with a low value.

\section{Operation as Battery Charging System}

This item shows the operation of the proposed system as battery charger, which occurs simultaneously with the SAPF operation mode. The main difference between these two modes of operation is the functioning of the dc-dc converter, which is deactivated when the system operates as SAPF only. However, during the battery charging operation mode, the dc-dc converter is controlled to charge the batteries with constant current and constant voltage, gathering the required power from the dc-link of the dc-ac converter, which is attained with the extra power component of the FBD power theory, as described in section II (a).

Fig. 3 illustrates the operation of the system as battery charger, showing the batteries voltage $\left(v_{b a t}\right)$ and current $\left(i_{b a t}\right)$ and the power grid voltage $\left(v_{s}\right)$ and current $\left(i_{s}\right)$. The batteries are charged with a $10 \mathrm{~A}$ constant current until the voltage of $29.6 \mathrm{~V}$, where the constant voltage charging stage takes place. This operation mode occurs when the dc-ac converter is operating as SAPF, therefore the grid current is sinusoidal and in phase with the grid voltage during the batteries charging, where a slightly higher grid current is perceived along the constant current charging state, representing the additional power component absorbed from the power grid necessary to this functionality. It is worth to mention that the necessary time to charge the batteries in this simulation result does not correspond to the charging time of real batteries, whereby a second-order electrical model of the batteries was used to diminish the simulation time.

\section{DEVELoped PRototype}

In this section, the developed laboratorial prototype is described in detail, where the digital control architecture and the power structure are analysed separately. Fig. 5 shows the developed prototype integrated in the laboratorial workbench, with its main parameters being presented in Table I.

\section{A. Control System}

The power converters present in the proposed system are controlled by means of a digital control architecture. For such purpose, a digital signal processor (DSP) was used, namely the model TMS320F28377S from Texas Instruments. Besides containing the digital control algorithms, this DSP has internal ADCs, DAC and several PWM output channels. In order to

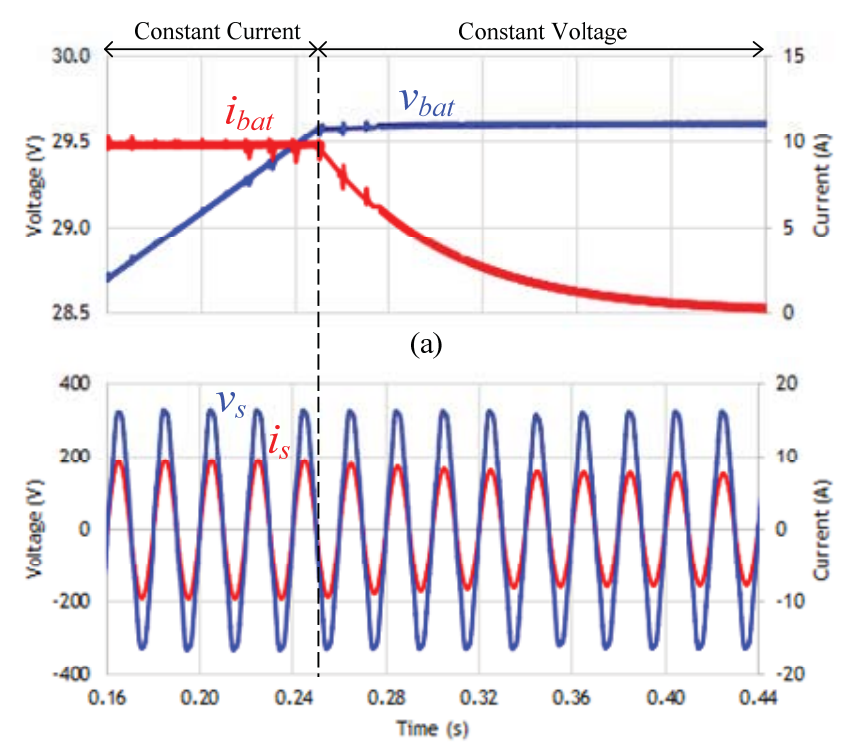

(b)

Fig. 3. Simulation results during battery charging operation: (a) Batteries voltage $\left(v_{b a t}\right)$ and current $\left(i_{b a t}\right)$; (b) Power grid voltage $\left(v_{s}\right)$ and current $\left(i_{s}\right)$.

acquire the necessary voltage and current signals, CYHVS5-25A and HAIS 50-P hall-effect current and voltage sensors are used. The output signals of the referred sensors need to be adapted to the ADC channels voltage range, whereby a signal conditioning circuit is used. It is also used a command circuit, inhibiting the power converters operation when an overvoltage or overcurrent is detected. The PWM outputs and the command signal are used as inputs for the power semiconductor gate driver circuits, in which the ADUM3223 from Analog Devices is used. Being a half-bridge gate driver, a total of six driver circuits were implemented.

\section{B. Power Stage}

The hardware power stage of the proposed system comprises two power converters, as previously mentioned. Both converters are described in this item.

\section{1) Dc-Ac Converter}

The dc-ac converter uses four IKW40N65F5 IGBTs from Infineon Technologies switched at a fixed frequency of $50 \mathrm{kHz}$. A protection circuit is used to prevent undesired switchings and overvoltages between the gate and emitter terminals. The dc-ac converter is connected to the power grid through a $1.2 \mathrm{mH}$ coupled inductor, added by a RC passive filter with a capacitance of $10 \mu \mathrm{F}$ and $8 \Omega$ damping resistor. For the dc-link, four $450 \mathrm{~V}$ capacitors connected in parallel are used, achieving a total capacitance of $3.28 \mathrm{mF}$.

\section{1) Bidirectional Isolated $D c-D c$ Converter}

The dual active bridge dc-dc converter is composed by four PSMN015-60PS NXP MOSFETs on the low voltage side and four IPP50R190CE Infineon MOSFETs on the high voltage side. These MOSFETs switch at $100 \mathrm{kHz}$ and the previously referred gate protection circuit is also used. In the batteries side, a $4.7 \mathrm{mF}$ capacitor is used to reduce the ripple in the batteries current. The galvanic isolation between both sides of 


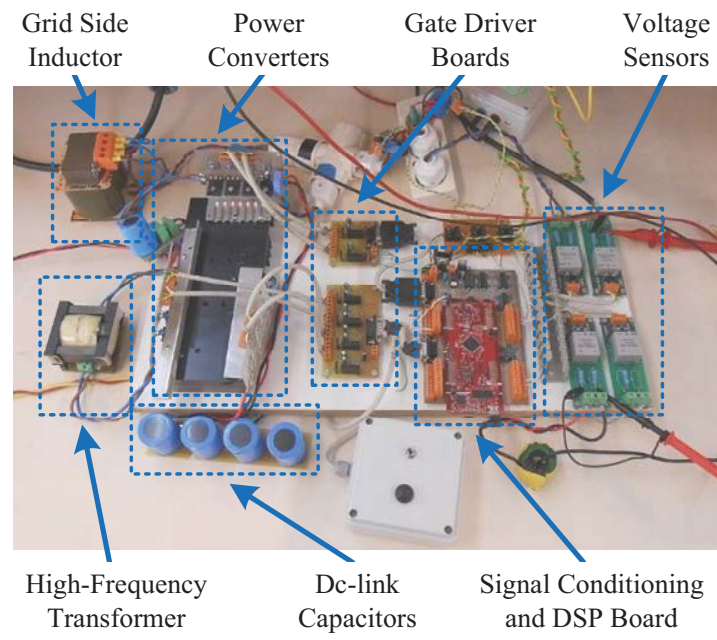

Fig. 5. Developed prototype integrated in the laboratorial workbench.

Table I. Developed prototype key parameters.

\begin{tabular}{c|c}
\hline \hline Parameter & Value \\
\hline \hline Power System & $230 \mathrm{~V}, 50 \mathrm{~Hz}$ \\
\hline Maximum Grid Current & $16 \mathrm{~A}$ \\
\hline Dc-link Voltage & $400 \mathrm{~V}$ \\
\hline Switching Frequency (dc-ac) & $50 \mathrm{kHz}$ \\
\hline Switching Frequency (dc-dc) & $100 \mathrm{kHz}$ \\
\hline HF Transformer Turns Ratio & $1: 15$ \\
\hline Maximum Power as UPS & $1 \mathrm{~kW}$ \\
\hline Batteries Voltage Range & $23 \mathrm{~V}$ to $29 \mathrm{~V}$ \\
\hline Maximum Batteries Current & $40 \mathrm{~A}$ \\
\hline \hline
\end{tabular}

the converter is attained with a high-frequency transformer developed for the proposed system, with a turns ratio of $1: 15$ and nominal currents of $45 \mathrm{~A}$ and $3 \mathrm{~A}$ for the primary and secondary, respectively. The transformer's core is based on ETD59, Epcos B66397G0000X187 N87 ferrite.

\section{EXPERIMENTAL VALIDATION}

This section depicts the main experimental results obtained with the developed prototype to validate the proper operation of the proposed system. Thus, this section is divided accordingly to the operation modes of SAPF and UPS. For safety reasons, the experimental results were obtained with the system connected to a power grid of $50 \mathrm{~V}$, with the dc-link reference voltage being established as $80 \mathrm{~V}$.

\section{A. Operation as $S A P F$}

This item shows the operation of the system as SAPF. Fig. 6 presents the power grid voltage $\left(v_{s}\right)$, the load current $\left(i_{L}\right)$, the dc-link voltage $\left(v_{d c}\right)$ and the SAPF reference current $\left(i_{c}{ }^{*}\right)$, acquired with the help of the DSP internal DAC, for a diode bridge rectifier with parallel RC load in the dc side and an inductor in the ac side. The result of the compensation is shown in Fig. 7, where are visible the grid voltage $\left(v_{s}\right)$ and current $\left(i_{s}\right)$ and the dc-link voltage $\left(v_{d c}\right)$. As it can be seen, the grid current is sinusoidal and in phase with the voltage with a total harmonic distortion (THD) of 3.6\%. As opposed to the previous scenario, the dc-link voltage is controlled to the established reference value.

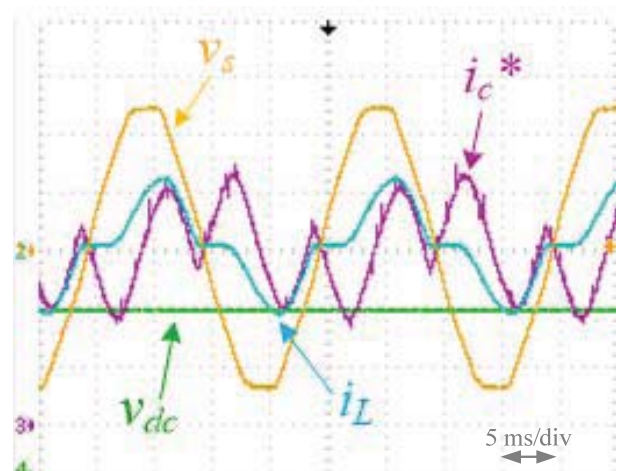

Fig. 6. Experimental results of the proposed system operating as normal SAPF: Grid voltage ( $\left.v_{s}: 20 \mathrm{~V} / \mathrm{div}\right)$; Load current $\left(i_{L}: 5 \mathrm{~A} / \mathrm{div}\right)$; Dc-link voltage $\left(v_{d c}: 20 \mathrm{~V} /\right.$ div); SAPF reference current $\left(i_{c}^{*}: 4 \mathrm{~A} /\right.$ div $)$.

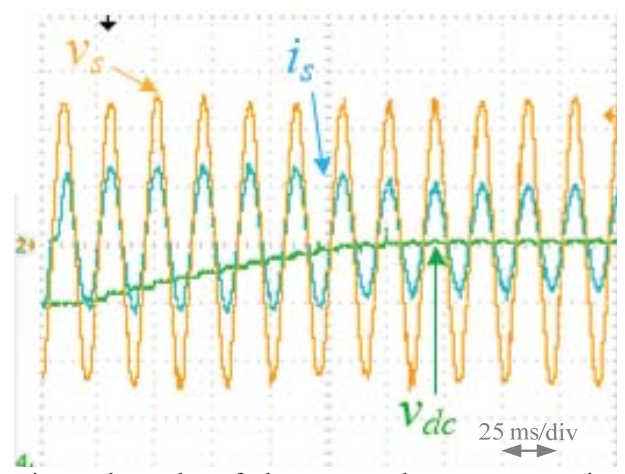

Fig. 7. Experimental results of the proposed system operating as normal SAPF: Grid voltage $\left(v_{s}: 20 \mathrm{~V} / \mathrm{div}\right)$; Grid current $\left(i_{s}: 5 \mathrm{~A} / \mathrm{div}\right)$; Dc-link voltage $\left(v_{d c}: 20 \mathrm{~V} / \mathrm{div}\right)$.

\section{B. Operation as UPS}

This item shows the operation of the system as UPS. A power outage detection can be seen in Fig. 8, as well as the grid voltage $\left(v_{s}\right)$, its rms value $\left(V_{s}\right)$ calculated by the DSP and a power outage indicative flag. This event is acknowledged in approximately $2 \mathrm{~ms}$ and the control algorithm is changed in order to the dc-ac converter synthesize a sinusoidal voltage. In Fig. 9 are depicted the voltage produced by the SAPF $\left(v_{f}\right)$, the dc-link voltage $\left(v_{d c}\right)$ and the current drawn by a diode bridge rectifier with parallel RC load and a low-value input inductor $\left(i_{f}\right)$. Even with the highly distorted current, the dc-ac converter successfully produces a low distortion sinusoidal voltage due to the implemented control scheme.

\section{CONCLUSION}

This paper presents a single-phase shunt active power filter (SAPF) with a bidirectional dc-dc converter for UPS operation. The operation principle of the proposed system is described, namely the operation modes (normal SAPF, UPS and battery charging system) and the implemented control algorithms for each system functionality. Simulation results are depicted to validate the theoretical operation of the proposed system. A reduced-scale laboratorial prototype was developed in order to obtain experimental results. Results for operation as normal SAPF and UPS modes are presented, proving the adequate operation of the proposed system in real conditions. The proposed SAPF with bidirectional dc-dc 


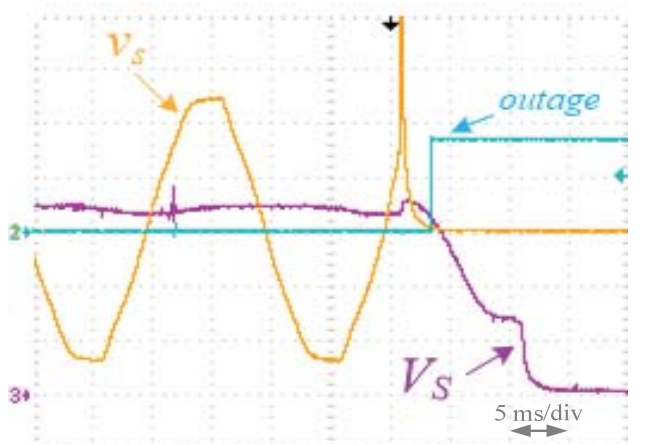

Fig. 8. Experimental results of the proposed system operating as UPS: Grid voltage $\left(v_{s}: 20 \mathrm{~V} / \mathrm{div}\right)$; Rms value of the grid voltage $\left(V_{s}: 20 \mathrm{~V} / \mathrm{div}\right)$; Power outage indicative flag (outage).

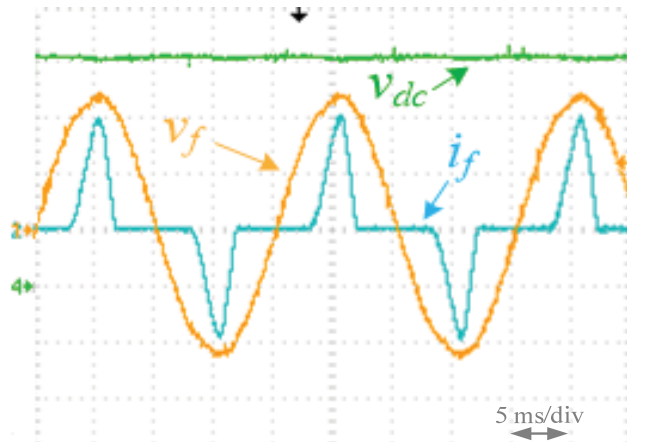

Fig. 9. Experimental results of the proposed system operating as UPS: SAPF output voltage $\left(v_{f}: 20 \mathrm{~V} /\right.$ div $)$; Load current $\left(i_{i}: 2 \mathrm{~A} /\right.$ div $)$; Dc-link voltage $\left(v_{d c}: 20 \mathrm{~V} / \mathrm{div}\right)$

converter for UPS operation can be an optimal solution for single-phase electrical systems, being able to compensate power quality problems in terms of current and voltage. The unified operation of both SAPF and UPS in the same device reduces the size and cost of the solution when compared to traditional separated devices, which is the main advantage of the proposed system.

\section{ACKNOWLEDGMENT}

This work has been supported by COMPETE: POCI-010145-FEDER-007043 and FCT - Fundação para a Ciência e Tecnologia within the Project Scope: UID/CEC/00319/2013. This work is financed by the ERDF - European Regional Development Fund through the Operational Programme for Competitiveness and Internationalisation - COMPETE 2020 Programme, and by National Funds through the Portuguese funding agency, FCT - Fundação para a Ciência e a Tecnologia, within project SAICTPAC/0004/2015- POCI01-0145-FEDER-016434.

\section{REFERENCES}

[1] A. Araújo, J. G. Pinto, B. Exposto, C. Couto, and J. L. Afonso, "Implementation and Comparison of Different Switching Techniques for Shunt Active Power Filters," IEEE IECON Industrial Electronics Society Conf., pp.1519-1525, Nov. 2014.

[2] Roger C. Dugan, Mark F. McGranaghan, S. Santoso, H. W. Beaty, "Electrical Power Systems Quality," McGraw-Hill (3rd Edition), pp. $373-435,2002$.
[3] J. G. Pinto, Bruno Exposto, Vitor Monteiro, L. F. C. Monteiro, Carlos Couto, João L. Afonso, "Comparison of Current-Source and VoltageSource Shunt Active Power Filters for Harmonic Compensation and Reactive Power Control," IEEE IECON Industrial Electronics Society Conf., pp.5124-5129, Oct. 2012.

[4] H. Sasaki, T. Machida, "A new method to eliminate ac harmonic currents by magnetic flux compensation - considerations on basic design," IEEE Trans. Power App. Syst., vol.PAS-90, no.5, pp.20092019, 1971.

[5] L. Gyugyi, E. C. Strycula, "Active AC Power Filters," IEEE IAS Industry Applications Society Annual Meeting, pp.529-535, 1976.

[6] H. Akagi, Y. Kanazawa, A. Nabae, "Instantaneous Reactive Power Compensators Comprising Switching Devices without Energy Storage Components," IEEE Trans. Ind. Appl., vol.IA-20, no.3, pp.625-630, May 1984.

[7] B. Singh, K. Al-Haddad, and A. Chandra, "A Review of active filters for power quality improvement," IEEE Trans. on Ind. Electron., vol.46, no.5, pp.960-971, Oct. 1999.

[8] Healthcare \& Public Health Sector Coordinating Councils, "Planning for Power Outages: A Guide for Hospitals and Healthcare Facilities," 2003.

[9] Neil Hodge, "Energy Risks - the dangers of power cuts and blackouts," Emerging Risks (Allianz), pp.28-33, 2015.

[10] J. P. Beaudet, J. N. Fiorina, and O. Pinon, "UPS topologies and standards," MGE-UPS Systems, 1999.

[11] A. Emadi, A. Nasiri, and S. B. Bekiarov, Uninterruptible Power Supplies and Active Filters. CRC Press, 2005.

[12] Chi Zhang, Josep M. Guerrero, Juan C. Vasquez, "A simplified control architecture for three-phase inverters in modular UPS application with shunt active power filter embedded," ECCE International Conf. on Power Electronics, pp.413-420, June 2015.

[13] Bruno Exposto, J. G. Pinto, H. Goncalves, Vitor Monteiro, D. Pedrosa, C. Couto, J. L. Afonso, "Evaluation of a Shunt Active Power Filter with energy backup capability," IEEE IECON Industrial Electronics Conf., pp.5963-5968, Nov. 2013.

[14] V. John and N. Mohan, "Standby power supply with high frequency isolation," IEEE APEC Applied Power Electronics Conf. and Exposition, pp.990-994, Mar. 1995.

[15] M. Depenbrock, "The FBD-method, a generally applicable tool for analyzing power relations," IEEE Trans. Power Syst., vol.8, no.2, pp.381-387, May 1993.

[16] Telmo Santos, J. G. Pinto, P. Neves, D. Gonçalves, João L. Afonso, "Comparison of Three Control Theories for Single-Phase Active Power Filters,” IEEE IECON Industrial Electronics Society Conf., Nov. 2009.

[17] M. Karimi-Ghartemani, M. R. Iravani, "A new phase-locked loop (PLL) system," IEEE MWSCAS Midwest Symposium on Circuits and Systems, vol.1, pp.421-424, Aug. 2001.

[18] R. W. A. A. De Doncker, D. M. Divan, M. H. Kheraluwala, “A ThreePhase Soft-Switched High-Power-Density DC/DC Converter for HighPower Applications," IEEE Trans. Ind. Appl., vol.27, no.1, pp.63-73, Jan. 1991

[19] J. Sebastian, J. A. Cobos, O. Garcia, J. Uceda, “An overall study of the half-bridge complementary-control DC-to-DC converter," IEEE PESC Power Electronics Specialist Conf., vol.2, pp.1229-1235, June 1995.

[20] Hua Bai, Chris Mi, "Eliminate Reactive Power and Increase System Efficiency of Isolated Bidirectional Dual-Active-Bridge DC-DC Converters Using Novel Dual-Phase-Shift Control," IEEE Trans. Power Electron., vol.23, no.6, pp.2905-2914, Dec. 2008.

[21] Kuiyuan Wu, Clarence W. de Silva, William G. Dunford, "Stability analysis of isolated bidirectional dual active full-bridge DC-DC converter with triple phase-shift control," IEEE Trans. Power Electron., vol.27, no.4, pp.2007-2017, Apr. 2012.

[22] Dehong Xu, Chuanhong Zhao, Haifeng Fan, "A PWM plus phase-shift control bidirectional dc-dc converter," IEEE Trans. Power Electron., vol.19, no.3, pp.666-675, May 2004. 